Research Article

\title{
Validation of Self-Reported Smoker and Second Hand Smoke Exposure by Urinary Cotinine within The Malaysian Cohort Project
}

\author{
Noraidatulakma Abdullah', Shariffah Huzaimah Al-Junid ${ }^{1}$, Mee Lee Looi ${ }^{1,2}$, Siok Fong Chin ${ }^{1}$, Ezanee \\ Azlina Mohd Haniff ${ }^{1}$, Syed Zulkifli Syed Zakaria ${ }^{3}$, Rahman Jamal ${ }^{*}$ \\ ${ }^{1}$ UKM Medical Molecular Biology Institute (UMBI), Universiti Kebangsaan Malaysia, Kuala Lumpur, Malaysia \\ ${ }^{2}$ Department of Pediatrics, Faculty of Medicine, Universiti Kebangsaan Malaysia, Kuala Lumpur, Malaysia \\ ${ }^{3}$ School of Biosciences, Taylor's University Lakeside Campus, No. 1, Jalan Taylor's, 47500 Subang Jaya, Selangor, \\ Malaysia
}

Article Info
History
Received : 21 Dec 2018
Accepted : 17 May 2019
Available : 27 July 2019

\begin{abstract}
Background: Validation of self-reported questionnaire is very crucial in ensuring the quality and reliability of data collection.

Objective: The aim of this study were i) to validate the questionnaire on tobacco smoke intake and second hand smoke exposure among The Malaysian Cohort (TMC) subjects through the determination of urinary cotinine levels, ii) to determine the optimal cut-off point of urine cotinine that discriminates smokers from non-smokers and iii) to estimate misclassification rate between self-reported smoking and urinary cotinine level..

Methods: Urine samples from a total of 775 The Malaysian Cohort subjects (104 smokers, 102 former smokers and 569 non-smokers) were obtained and urinary cotinine levels were determined by high-performance liquid chromatography (HPLC). Correlation between self-reported questionnaires and urinary cotinine were compared using Spearman's correlation tests. The Receiver Operating Characteristic (ROC) curved was performed to define the optimal cut-off point and the diagnostic ability of urinary cotinine.
\end{abstract}

Results: Urinary cotinine concentration significantly $(p<0.001)$ correlated with smoking status $(\mathrm{r}=0.46)$, the average number of cigarettes smoked per day $(\mathrm{r}=0.53)$, duration of smoking $(\mathrm{r}=0.33)$ and number of cigarettes packed per year $(\mathrm{r}=0.47)$. Smokers and second hand smokers have significantly higher median cotinine levels (978.40 and 21.31 respectively) compared to non-smokers (15.52) and non-exposed (13.60) subjects. Cotinine level at cut-off value of $1.51 \mathrm{ng} / \mathrm{mg}$ creatinine is able to distinguish smokers and non-smokers with a sensitivity of $45.8 \%$, specificity of $96.7 \%$, $84.6 \%$ positive predictive value and $81.7 \%$. negative predictive value. The false positive rate and false negative rate were low with $15.4 \%$ and $18.3 \%$, respectively.

Conclusion: Cotinine level of $1.51 \mathrm{ng} / \mathrm{mg}$ creatinine indicated the optimal cut-off value to distinguish smokers and non-smokers. Self-reported smoking questionnaire showed significant correlation with urinary cotinine and indicated only small misclassification rate. Thus, the self-reported smoking questionnaire can be used to assess smoking exposure with careful interpretation.

Keywords: Urine Cotinine, Self-reported Tobacco intake, second hand smoke. Permalink/ DOI: https://doi.org/10.14710/jbtr.v5i1.3971

\section{INTRODUCTION}

Tobacco smoking is the main cause of premature and preventable deaths worldwide. It is estimated that smoking kills 20,000 Malaysians annually and will increase to 30,000 by the year 2020 if the pattern of smoking remains the same ${ }^{1}$. The prevalence of current smoker in Malaysia was $22.8 \%$ reported by The National Health Morbidity Survey 2015 (95\%CI: 21.9, 23.8) with 
* Corresponding author:

E-mail: rahmanj@ppukm.ukm.edu.my (Rahman Jamal)

nearly five million Malaysians aged 15 years and above estimated as smokers ${ }^{1}$. The smoking prevalence was comparable with India $(24.3 \%)$ but lower than other neighboring countries such as Thailand (45.6\%), Vietnam (50\%), Philippines (53.8\%) and China (66.9\%) 2,3 . In addition, the prevalence of exposure to second hand smoke (smokers and non-smokers) in Malaysia was $37.1 \%$ (95\%CI: 35.6, 38.6). Smoking accounted for $16.49 \%$ of the National Health Expenditure in Malaysia or $0.74 \%$ of the GDP. The burden of smoking related diseases; chronic obstructive pulmonary diseases, ischemic heart disease, and lung cancer were $67.53 \%$ of the total health care cost with an estimate of RM $1,974,950,532.78$ (US\$ 533,770,414) ${ }^{4}$.

Conventionally, smoking is often assessed by questionnaire due to feasibility and cost effectiveness, however this method is prone to bias and may lead to underestimation of the true prevalence ${ }^{5,6}$. Recall bias and denial due to social stigma are the main source of selfreporting bias especially when the subjects are under pressure because of social or medical disapproval, misunderstanding, intentional deception, embarrassment and shame ${ }^{7-10}$. A number of studies have made an effort to validate self-reported smoking, for example by using exhaled carbon monoxide ${ }^{11-13}$, serum, plasma or urine levels of nicotine ${ }^{14}$ and also urinary cotinine ${ }^{15-17}$. Nicotine is the primary metabolite that plays important role in tobacco addiction ${ }^{9}$. Thus cotinine, the major metabolite of nicotine, is currently regarded as the best biomarker to detect primary and second hand smokers ${ }^{18}$. To date, biochemical verification on urine cotinine is globally accepted as the gold standard in determining smoking status due to its longer half-life ( $>20$ hours), specificity to nicotine intake, five times higher level in the urine compared to other biological matrixes ${ }^{19,20,21}$ and ability to distinguish smokers from non-smokers ${ }^{18,22,23}$.

The questionnaire which were used for assessment of tobacco smoke intake and second hand smoke exposure was a modified version of the Global Adult Tobacco Survey (GATS) from the Global Tobacco Surveillance. This tool was design to monitor adult tobacco used and generate comparable data within and across countries systematically. In addition, it is also feasible, cost effective and can be used in population setting. The results from the survey eventually help public health authority to enhance capacity to design, implement and evaluate tobacco control interventions ${ }^{24-25}$.

It is crucial to validate the TMC tobacco smoke intake questionnaire since the outcome can be used for documenting the extent of the tobacco epidemic, estimating population risk and smoking-attributable disease burden, and evaluating the progress of tobacco control programs ${ }^{26}$.

The aims of this study were; i) to assess the validity of self-reported TMC questionnaire on tobacco smoke intake and secondhand smoke exposure using urinary cotinine concentration, ii) to determine the optimal cutoff point of urine cotinine that discriminates smokers from non-smokers and iii) to estimate misclassification rate between self-reported smoking and urinary cotinine level.

\section{MATERIALS AND METHODS}

\section{Data sources and study samples}

The study sample was selected from the Malaysian Cohort Project (TMC), a prospective population-based cohort including 106,527 volunteers aged between 35 and 70 years old ${ }^{27}$. Subjects were recruited between April 2006 and September 2012 from regions across Malaysia. For this cross-sectional study, a total of 775 subjects which comprised of 104 smokers, 102 former smokers and 569 non-smokers were randomly selected. Those who underwent nicotine replacement therapy during the recruitment were excluded from this study. All subjects gave written informed consent to participate in the study.

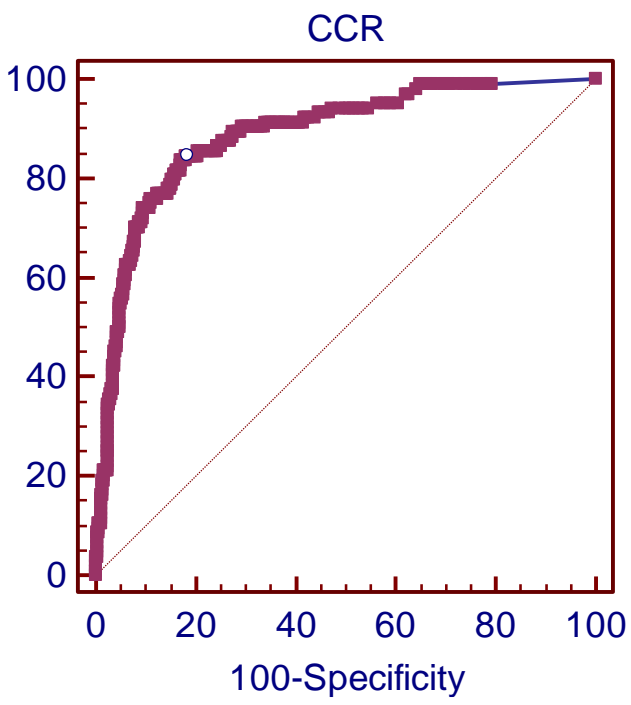

Figure 1: Receiver Operating Curve Characteristics (ROC) of the normalised cotinine level measured as cotinine in ng per creatinine in mg. Smokers were well differentiated from non-smokers; AUC: 0.89.

\section{Self-reported smoking and related status}

Current smokers were defined as those who responded affirmatively to questions on: i) ever use of tobacco products, ii) smoked at least 100 sticks cigarettes in entire life, and iii) still smoking. Ex-smokers were those responded positively to the question (i) and (ii) and negative for (iii) (Supplementary data). Conversely, the non-smokers were defined as those who responded negatively to all three questions. Non-smokers were further divided into (i) passive smokers, who were exposed to second hand smoke either from family and workplace and (ii) non-smokers who have no exposure to second hand smoke. Others information related to smoking were also recorded such as quantity of cigarettes, duration of smoking, age started to smoke and type of tobacco used .

\section{Urinary cotinine determination}

Urine samples were collected prior to 8 hours fasting. Urinary cotinine were extracted and measured by using the high performance liquid chromatography (HPLC) 
system (Agilent 1200 Series) according to the method described previously with slight modifications ${ }^{28}$. Briefly, urine samples were hydrolysed with $10 \mathrm{M}$ sodium hydroxide, followed by liquid-liquid extraction with dichloromethane. The extracts were dried under nitrogen stream and reconstituted with $200 \mu$ l mobile phase comprised of $0.07 \mathrm{M}$ citric acid: $0.1 \mathrm{M}$ sodium acetate: acetonitrile: methanol (10:5:3:2), pH 4.4 adjusted by acetic acid. Cotinine was eluted isocratically on a LC-8-DB Supelcosil column (250 mm X $5 \mu \mathrm{m}$ ID) and detected by photodiode array detector at $260 \mathrm{~nm}$. The detection limit of this method is $5 \mathrm{ng} / \mathrm{ml}$. The cotinine levels were subsequently normalized with

Table 1: Demographic data of the study $(\mathrm{n}=775)$

\begin{tabular}{|c|c|c|}
\hline \multicolumn{2}{|c|}{ Characteristic } & \multirow{2}{*}{$\frac{\mathbf{N}(\%)}{75(9.6)}$} \\
\hline Age (years) & $<40$ & \\
\hline & $41-50$ & $303(39.1)$ \\
\hline & $51-60$ & $315(40.7)$ \\
\hline & $>61$ & $82(10.6)$ \\
\hline \multirow[t]{2}{*}{ Gender } & Male & $375(48.4)$ \\
\hline & Female & $400(51.6)$ \\
\hline \multirow[t]{4}{*}{ Ethnic groups } & Malays & $193(24.9)$ \\
\hline & Chinese & $441(56.9)$ \\
\hline & Indian & $134(17.3)$ \\
\hline & Others & $7(0.9)$ \\
\hline \multirow[t]{4}{*}{$\begin{array}{l}\text { Education } \\
\text { level }\end{array}$} & $\begin{array}{l}\text { No formal } \\
\text { education }\end{array}$ & $37(4.8)$ \\
\hline & Primary & $106(13.7)$ \\
\hline & Secondary & $378(48.8)$ \\
\hline & Tertiary & $254(32.8)$ \\
\hline \multirow[t]{4}{*}{ Marital status } & Single & $61(7.9)$ \\
\hline & Married & $652(84.1)$ \\
\hline & Widowed & $38(4.9)$ \\
\hline & Divorced & $24(3.1)$ \\
\hline \multirow[t]{2}{*}{$\begin{array}{l}\text { Working } \\
\text { status }\end{array}$} & Working & $291(37.5)$ \\
\hline & Not working & $484(62.5)$ \\
\hline \multirow{10}{*}{$\begin{array}{l}\text { Type of } \\
\text { tobacco use }\end{array}$} & Filtered kretek & $201(25.9)$ \\
\hline & White cigarette & $197(25.4)$ \\
\hline & $\begin{array}{l}\text { Filtered white } \\
\text { cigarette }\end{array}$ & $196(25.3)$ \\
\hline & Kreteks & $30(3.9)$ \\
\hline & $\begin{array}{l}\text { Paper cigarette } \\
\text { (rokok daun) }\end{array}$ & $14(1.8)$ \\
\hline & Cigar & $5(0.6)$ \\
\hline & Pipe & $5(0.6)$ \\
\hline & Cheroot & $4(0.5)$ \\
\hline & Bidis & $3(0.4)$ \\
\hline & Chewed tobacco & $3(0.4)$ \\
\hline
\end{tabular}

urinary creatinine $(\mathrm{Cr})$ and the data were reported as cotinine/creatinine ratio $(\mathrm{CCR}),(\mathrm{ng} / \mathrm{mg} \mathrm{Cr})$. The urinary creatinine levels were measured by using Urinary Creatinine Detection Kit (Arbor Assays; Luminos USA) with absorbance values read by using microplate reader (Biotek, US) at $\lambda=490 \mathrm{~nm}$. Urinary cotinine levels were analysed as both adjusted and unadjusted values by creatinine level.

\section{Statistical Analyses}

Non-parametric test was done due to the fact that the distribution of the data was not normal even though data transformation has been applied. Differences between groups were compared using Kruskal Wallis and MannWhitney tests. Correlation between urine cotinine concentration with smoking characteristics were analysed using Spearman's rank correlation.

The Receiver Operating Characteristic (ROC) curve was performed to obtain the optimal cut off to discriminate smokers from non-smokers as well as passive smokers and non-smokers. The optimal cut-off point commonly used Youden index $(\mathrm{J})$ method $^{29}$. This method defines the optimal cut-point as the point maximizing the Youden function which was the difference between true positive rate and false positive rate over all possible cut-point values. An optimal cutpoint was referred when the point classifies most of the individuals correctly. ROC curve mapped the sensitivity versus 100 - specificity for all possible values of the cutpoint between smokers and non-smokers.

A cut-off point of cotinine level in the urine with $\mathrm{AUC}=$ 100 discriminates individuals perfectly as smokers, while, an $\mathrm{AUC}=50$ means that there was no substantial difference between the level of urinary cotinine values of the two groups (smokers and non-smokers) ${ }^{29}$.

A significance threshold was set at $\mathrm{p}<0.05$. All statistical analyses were conducted using IBM SPSS (Version 19).

\section{RESULTS}

Based on the self-reported tobacco smoking questionnaire, a total of $104(13.4 \%)$ smokers, 101 (13.0\%) ex-smokers and $570(73.6 \%)$ non-smokers were classified based on different ethnic groups: Chinese $(56.9 \%)$, Malay (24.9\%), Indian (17.3\%) and others $(0.9 \%)$ (Table 1 and Table 2). In general, majority of the

Table 3: Correlation between urinary cotinine concentration with self reported tobacco intake questionnaire

\begin{tabular}{ccc} 
Item & $\begin{array}{c}\text { Correlation } \\
\text { coefficient } \\
(\mathbf{r})\end{array}$ & $\begin{array}{c}\mathbf{p} \\
\text { value }\end{array}$ \\
\hline Smoking status & 0.46 & $0.001^{*}$ \\
Average cigarettes & 0.53 & $0.001^{*}$ \\
$\quad$ smoked per day & -0.08 & 0.443 \\
Age started to smoke & 0.33 & $0.001^{*}$ \\
Smoking duration (years) & 0.47 & $0.001^{*}$ \\
$\begin{array}{c}\text { Smoking history } \\
\text { (packed/years) }\end{array}$ & & \\
\hline
\end{tabular}


subjects were female, married (84.1\%), aged between 51 to 60 years old $(40.7 \%)$, had secondary education $(48.8 \%)$, unemployed $(62.5 \%)$ and smoking using white cigarette/ filtered white cigarette $(50.7 \%)$ (Table 1).
Most of the subjects have reported previous history of smoking more than 20 packs of cigarettes per year $(36.54 \%)$. However, the median of urinary cotinine and CCR were highest in subjects with history of smoking 11

Table 2: Urinary cotinine and cotinine/creatinine ratio (CCR) levels by smoking characteristics

\begin{tabular}{|c|c|c|c|c|}
\hline \multirow[b]{2}{*}{ Smoking characteristics } & \multirow[b]{2}{*}{$\mathbf{n}$} & \multirow[b]{2}{*}{$\%$} & \multirow{2}{*}{$\begin{array}{c}\begin{array}{c}\text { Cotinine concentration } \\
(\mathrm{ng} / \mathrm{ml})\end{array} \\
\text { Median } \pm(\mathbf{I Q R}) \\
\end{array}$} & \multirow{2}{*}{$\begin{array}{c}\text { CCR (ng/mg } \\
\text { Creatinine) } \\
\text { Median } \pm(\text { IQR) }\end{array}$} \\
\hline & & & & \\
\hline \multicolumn{5}{|l|}{ Smoking status } \\
\hline Smoker & 104 & 13.42 & $978.4(1612.75)$ & $9.72 \pm(20.12)$ \\
\hline Ex-Smoker & 101 & 13.03 & $17.85(54.16)^{\mathrm{a}}$ & $0.22 \pm(0.82)^{\mathrm{a}}$ \\
\hline Non-smoker & 570 & 73.55 & $15.50(34.25)^{\mathrm{a}}$ & $0.29 \pm(0.84)^{\mathrm{a}}$ \\
\hline \multicolumn{5}{|l|}{$\begin{array}{c}\text { Smokers } \\
\text { Averaged number of } \\
\text { cigarette smoked per day }\end{array}$} \\
\hline$<10$ & 52 & 50.01 & $454.62(1021.98)$ & $4.80(15.35)$ \\
\hline 11 to 20 & 42 & 40.38 & $1328.26(1398.66)^{\mathrm{b}}$ & $17.46(30.04)^{\mathrm{b}}$ \\
\hline$>20$ & 10 & 9.61 & $1196.65(1349.28)^{\mathrm{b}}$ & $15.06(42.06)^{\mathrm{b}}$ \\
\hline \multicolumn{5}{|l|}{ Age started smoking } \\
\hline$<17$ & 27 & 25.96 & 876.17 (1094.87) & $10.31(19.19)$ \\
\hline $18-25$ & 61 & 58.65 & $1160.28(1793.56)$ & $14.15(32.73)$ \\
\hline$>25$ & 16 & 15.38 & $609.87(1110.35)$ & $6.19(10.42)$ \\
\hline \multicolumn{5}{|l|}{ Tobacco smoking history (pack-years) } \\
\hline$<10$ & 34 & 32.69 & $278.62(685.81)$ & $2.69(7.18)$ \\
\hline 11 to 20 & 29 & 27.88 & $1160.28(1730.60)^{\mathrm{c}}$ & $17.35(37.81)^{\mathrm{c}}$ \\
\hline$>20$ & 38 & 36.54 & $1350.41(1317.56)^{\mathrm{c}}$ & $15.37(30.98)^{\mathrm{c}}$ \\
\hline \multicolumn{5}{|l|}{ Non-smokers } \\
\hline $\begin{array}{l}\text { No second hand smoke exposure at } \\
\text { home and workplace }\end{array}$ & 264 & 46.4 & $13.60(30.36)$ & $0.28(0.79)$ \\
\hline Second hand smoke exposure at home & 96 & 16.87 & $21.31(62.47)^{\mathrm{d}}$ & $0.44(1.41)$ \\
\hline $\begin{array}{l}\text { Second hand smoke exposure at } \\
\text { workplace }\end{array}$ & 143 & 25.13 & $15.19(47.76)^{\mathrm{d}}$ & $0.28(1.02)$ \\
\hline
\end{tabular}

Smokers showed significantly higher median of urine cotinine and CCR (urine cotinine: $978.4 \mathrm{ng} / \mathrm{ml}$; CCR: $9.72 \mathrm{ng} / \mathrm{mg} \mathrm{Cr}$ ) as compared to ex-smokers (urine cotinine: $17.85 \mathrm{ng} / \mathrm{ml}$; CCR: $0.22 \mathrm{ng} / \mathrm{mg} \mathrm{Cr}$ ) and nonsmokers (urine cotinine: $15.50 \mathrm{ng} / \mathrm{ml}$; CCR: $0.29 \mathrm{ng} / \mathrm{mg}$ $\mathrm{Cr}$ ). The levels of urine cotinine and CCR were significantly increased in smokers who reported intake of 11-20 cigarettes per day in comparison to less than 10 cigarettes per day, $1328.26 \mathrm{ng} / \mathrm{ml}$ vs. $454.62 \mathrm{ng} / \mathrm{ml}$ and 17.46 ng/mg Cr vs. $4.81 \mathrm{ng} / \mathrm{mg} \mathrm{Cr}$ ), respectively (Table 2). Similar increment was observed in smokers with more than 20 cigarettes per day as compared to those with less than 10 cigarettes per day (urine cotinine: $1196.65 \mathrm{ng} / \mathrm{ml}$ vs. $454.62 \mathrm{ng} / \mathrm{ml}$ and CCR: $15.06 \mathrm{ng} / \mathrm{mg}$ $\mathrm{Cr}$ vs. $4.80 \mathrm{ng} / \mathrm{mg} \mathrm{Cr}$ ). More than half of the subjects had started smoking at the age of $18-25$ years old $(58.65 \%)$ and this data is in agreement with the levels of urine cotinine and CCR measured in which the highest median was shown by this age group (Table 2). to 20 packs per year. Second hand smoke exposure at home and at workplace showed significant difference in urinary cotinine level compared to no exposure with the highest level of cotinine found in subjects who had reported exposure at home, followed by exposure at workplace.

In addition, we found that the creatinine-adjusted urinary cotinine levels were positively correlated with smoking status $(\mathrm{r}=0.46, \mathrm{p}=0.001)$, averaged number of cigarettes smoked per day $(\mathrm{r}=0.53, \mathrm{p}=0.001)$, smoking duration $(\mathrm{r}=0.33, \mathrm{p}=0.001)$ and smoking history (number of pack per year) $(\mathrm{r}=0.47, \mathrm{p}=0.001)$ as per self-reported questionnaires (Table 3).

The cut-off point for cotinine at $1.51 \mathrm{ng} / \mathrm{mg} \mathrm{Cr}$ gave a good discrimination between smokers and non-smoker as showed by the Receiver Operating Characteristic (ROC) curve with area under the curve, AUC $=0.89$ (Figure 2). Majority of the smokers had urinary cotinine level more than $1.51 \mathrm{ng} / \mathrm{mg} \mathrm{Cr}(84.6 \%)$, while $81.7 \%$ non-smokers and $84.3 \%$ ex-smokers had urinary cotinine 
Table 4: Contingency table of Cotinine concentration at cut off value of $1.51 \mathrm{ng} / \mathrm{mg}$ creatinine

\begin{tabular}{llll}
\hline & & Number of subjects, $\mathbf{n}(\%)$ & \\
\hline $\begin{array}{l}\text { Smoking } \\
\text { status }\end{array}$ & $\begin{array}{l}\text { Cotinine concentration }>\mathbf{1 . 5 1} \mathbf{~ n g} / \mathbf{m g} \\
\text { creatinine }\end{array}$ & $\begin{array}{l}\text { Cotinine concentration } \leq \mathbf{1 . 5 1} \mathbf{~ n g} / \mathbf{m g} \\
\text { creatinine }\end{array}$ & Total \\
\hline Smokers & $88(84.6)$ & $16(15.4)$ & 104 \\
Ex-smokers & $16(15.7)$ & $86(84.3)$ & 102 \\
Non-smokers & $104(18.3)$ & $465(81.7)$ & 569 \\
Total & $208(26.84)$ & $567(73.16)$ & 775 \\
\hline
\end{tabular}

Table 5: Diagnostic parameters of cotinine concentration.

\begin{tabular}{lllcl}
\hline & & \multicolumn{3}{c}{ Cotinine concentration } \\
\hline Self-reported smoking & $\begin{array}{l}\text { Smoking } \\
\text { status } \\
\text { Smokers }\end{array}$ & Smokers & Non-smokers & \\
& & $88(\mathrm{TP})$ & $16(\mathrm{FP})$ & PPV: 0.85 \\
& Non-smokers & $104(\mathrm{FN})$ & $465(\mathrm{TN})$ & NPV: 0.82 \\
& Sensitivity: 0.46 & Specificity: 0.97 &
\end{tabular}

TP: True Positive, FP: False Positive, FN: False Negative, TN: True Negative, PPV: Positive Predictive Value, NPV: Negative Predictive Value

level less than $1.51 \mathrm{ng} / \mathrm{mg} \mathrm{Cr}$ (Table 4). The cut-off value also gave a good diagnostic accuracy results with sensitivity of $42.3 \%, 96.7 \%$ specificity, $84.6 \%$ positive predictive value and $81.7 \%$ negative predictive value. The false positive rate and false negative rate were low with $15.4 \%$ and $18.3 \%$, respectively (Table 5). The prevalence of smoking was lower based on self- reported questionnaire (13.42\%) as compared to prevalence using cotinine levels above $1.51 \mathrm{ng} / \mathrm{mg} \mathrm{Cr}(26.84 \%)$.

\section{DISCUSSION}

Based on the self-reported data, the prevalence of smoking from this study was $13.42 \%$ which was lower than the recent prevalence data from the Malaysia National Health and Morbidity Survey (22.8\%) ${ }^{1}$. However, based on the laboratory results obtained in this current study, prevalence value was slightly higher (26.84\%) and closed to the value reported by the Malaysia National Health and Morbidity Survey. The discrepancy of the prevalence might be due to the underreporting of the result. This is consistent with previous study that also found underestimation of self-reported smoking while cotinine was considered as more accurate biomarker of smoke exposure ${ }^{30}$. In this study, we found smokers have significantly higher levels of urinary cotinine as compared to ex-smokers and non-smokers. There was a relationship between urinary cotinine and smoking among the smokers with the higher number of cigarettes smoked per day correlated with higher levels of the measured urinary cotinine. In addition, the questionnaire items which were smoking status, averaged number of cigarettes smoked per day, smoking duration and number of cigarettes packed per year indicated significantly moderate correlation $(0.33-0.47)$ with urine cotinine. These results were consistent with other findings conducted in a similar population ${ }^{14}$. The results showed that, although self-reporting questionnaires typically underestimate the smoking rate, such outcomes are still highly consistent with those determined through a urinary test. Thus, self-reporting questionnaires can serve as an effective tool for assessing smoking behaviour. Taken together, these results indicated that our questionnaires are consistent in capturing smoking and secondhand smoker status.

To date, there is no standardised urinary cotinine cutoff value for differentiating smokers from non-smoker. It remains arbitrary due to the overlap between nonsmokers who are highly exposed to second hand smoke and occasional smokers or those who inhale very little smoke. Our study indicate that the cotinine cut-off value of $1.51 \mathrm{ng} / \mathrm{mg} \mathrm{Cr}$ was an optimal value to distinguish the smoking status with an acceptable sensitivity and specificity in the Malaysian population. However, our proposed cut-off value was higher than the value reported from a population study among young Malaysian adults in $2009^{14}$. It is important to note that our data used adjusted creatinine-corrected cotinine level for differences in urinary excretion volume whereas the latter was without creatinine normalization. Moreover, the difference in population age may contribute to the discrepancy, as younger adult smokers are likely in the process of becoming established smokers.

Nonetheless, the disparity of the cut-off value is very much dependent on the concentration of the urinary 
cotinine. The concentration of urinary cotinine are reliant on individual variability such as the duration and the intensity of exposure or smoking, the pattern of smoking and nicotine uptake, metabolism and elimination rate ${ }^{31-33}$. Furthermore, the cut-off points of urinary cotinine may also be influenced by ethnic specificity due to racial differences in nicotine pharmacokinetics and genetic polymorphisms ${ }^{10-34}$.

The range of misclassification between self-reported non-smokers and ex-smokers obtained in this study using the optimal urinary cotinine cut-off value of 1.51 $\mathrm{ng} / \mathrm{mg} \mathrm{Cr}$ was in accordance with another study conducted in the Aboriginal population ${ }^{35}$.However, some studies reported a wider range, between $6.4 \%$ to $57.1 \%$ in Aboriginal and Indian populations ${ }^{36,37}$. In spite of this, the comparison of smoking misclassification across studies needs to be interpreted cautiously as each study is different in terms of design and methodology such as the cut off points to distinguish smokers from non-smokers, the use of creatinine normalization, study settings (clinical settings compared with community based studies), denominators used for misclassification rates (smokers compared with non-smokers), analytical techniques (gas chromatography compared with radioimmunoassay), racial differences in nicotine metabolism, education level, past smoking history and smoking habits (smoking behaviours that may affect nicotine intake $)^{9,10,34}$. In this study, measurement of cotinine level was performed by using HPLC tool, which provides superior sensitivity and specificity as compared to other biochemical techniques used in cotinine quantitation such as enzyme-linked immunosorbent assay $^{38}$ and colorimetric-based autoanalyser assay ${ }^{39}$, but more cost effective as compared to higher end mass spectrometry $^{40}$ and radioimmunoassay ${ }^{41}$. The positive correlation between the measured creatinine-adjusted urinary cotinine and smoking status demonstrates the reliability of this practical yet economical approach for evaluating exposure to smoking, especially in laboratories not equipped with high-end mass spectrometry system.

The grey zone still exists between occasional smokers and non-smokers exposed to second hand smoke, where differentiation is deemed challenging. This is further supported by the fact that the serum cotinine level in these occasional smokers decreased rapidly in a short period of time as compared to their 'heavier' counterparts ${ }^{10}$. Nevertheless, the use of a biological marker such as cotinine as applied in this study to validate self-reported data on smoking is relevant as recall bias and social stigma have been implicating the accuracy of the self-reported data in the form of questionnaire where under-reporting of the true smoking event was consistently observed ${ }^{10}$. Apart from its applicability for validating self-reported smoking data, this urinary cotinine assessment can be incorporated as additional assessment on high-risk population who is exposed to second-hand smoke towards smoking-related diseases. Nonetheless, more studies are needed to link those diseases to cotinine levels with careful interpretation particularly in relation to the cut-off points prior to its clinical application.

\section{CONCLUSION}

Cotinine level of $1.51 \mathrm{ng} / \mathrm{mg}$ creatinine indicated the optimal cut-off value to distinguish smokers and nonsmokers. Self-reported smoking questionnaire showed significant correlation with urinary cotinine and indicated only small misclassification rate. Thus, the self-reported smoking questionnaire can be used to assess smoking exposure with careful interpretation.

\section{ACKNOWLEDGMENTS}

We thank all UKM Medical Molecular Biology Institute (UMBI) and The Malaysian Cohort staff members and research assistants. The voluntary participation of all the subjects is greatly appreciated.

\section{REFERENCES}

1. Institute of Public Health (IPH). National Health \& Morbidity Survey (NHMS 2015). In: Ministry of Health Malaysia, editor. 2015. p. 315.

2. Chinese Center for Disease Control and Prevention. Global Adult Tobacco Survey (GATS) China 2010 Country Report. In: GATS China National Office, editor. 2010.

3. Lim HK, Ghazali SM, Kee CC, Lim KK, Chan YY, Teh HC, et al. Epidemiology of smoking among Malaysian adult males: prevalence and associated factors. BMC public health. 2013;13:8.

4. Syed Junid S. Health Care Cost Of Smoking In Malaysia In: National University of Malaysia, editor. Kuala Lumpur: UKM; 2007.

5. Park MB, Kim CB, Nam EW, Hong KS. Does South Korea have hidden female smokers: discrepancies in smoking rates between self-reports and urinary cotinine level. BMC women's health. 2014;14:156.

6. Jung-Choi KH, Khang YH, Cho HJ. Hidden female smokers in Asia: a comparison of self-reported with cotinine-verified smoking prevalence rates in representative national data from an Asian population. Tobacco control. 2012;21(6):536-42.

7. Evans-Polce RJ, Castaldelli-Maia JM, Schomerus G, Evans-Lacko SE. The downside of tobacco control? Smoking and self-stigma: A systematic review. Social science \& medicine. 2015;145:26-34.

8. Ozoh OB, Dania MG, Irusen EM. The Prevalence of Self-Reported Smoking and Validation with Urinary Cotinine Among Commercial Drivers in Major Parks in Lagos, Nigeria. Journal of public health in Africa. 2014;5(1):316.

9. Rebagliato M. Validation of self reported smoking. Journal of epidemiology and community health. 2002;56(3):163-4.

10. Caraballo RS, Giovino GA, Pechacek TF, Mowery PD. Factors associated with discrepancies between self-reports on cigarette smoking and measured serum cotinine levels among persons aged 17 years or older: Third National Health and Nutrition Examination Survey, 1988-1994. American journal of epidemiology. 2001;153(8):807-14.

11. Maclaren DJ, Conigrave KM, Robertson JA, Ivers RG, Eades S, Clough AR. Using breath carbon monoxide to validate self-reported tobacco smoking in remote Australian Indigenous communities. Population health metrics. 2010;8(1):2. 
12. Pearce MS, Hayes L, Newcastle Heart P, Newcastle Thousand Families S. Self-reported smoking status and exhaled carbon monoxide: results from two population-based epidemiologic studies in the North of England. Chest. 2005;128(3):1233-8.

13. Morabia A, Bernstein MS, Curtin F, Berode M. Validation of self-reported smoking status by simultaneous measurement of carbon monoxide and salivary thiocyanate. Preventive medicine. 2001;32(1):82-8.

14. Man CN, Fathelrahman AI, Harn GL, Lajis R, Samin AS, Omar M, et al. Correlation between urinary nicotine, cotinine and self-reported smoking status among educated young adults. Environmental toxicology and pharmacology. 2009;28(1):92-6.

15. Chiu YL, Huang SJ, Lai CH, Huang CC, Jiang SH, Li SR, et al. Validation of Self-reported Smoking with Urinary Cotinine Levels and Influence of Second-hand Smoke among Conscripts. Scientific reports. 2017;7(1):15462.

16. Valladolid-Lopez Mdel C, Barrientos-Gutierrez T, Reynales-Shigematsu LM, Thrasher JF, PelaezBallestas I, Lazcano-Ponce E, et al. Evaluating the validity of self-reported smoking in Mexican adolescents. BMJ Open. 2015;5(10):e007485.

17. Jarvis MJ, Tunstall-Pedoe H, Feyerabend C, Vesey C, Saloojee Y. Comparison of tests used to distinguish smokers from nonsmokers. Am J Public Health. 1987;77(11):1435-8.

18. Verification SSoB. Biochemical verification of tobacco use and cessation. Nicotine \& tobacco research : official journal of the Society for Research on Nicotine and Tobacco. 2002;4(2):149-59.

19. Alberg AJ, Worley ML, Tooze JA, Hatcher JL, Carpenter MJ, Day TA, et al. The Validity of Selfreported Recent Smoking in Head and Neck Cancer Surgical Patients. Otolaryngology--head and neck surgery : official journal of American Academy of Otolaryngology-Head and Neck Surgery. 2015;153(6):990-5.

20. Benowitz NL. Cotinine as a biomarker of environmental tobacco smoke exposure. Epidemiologic reviews. 1996;18(2):188-204.

21. Matsumoto A, Matsumoto A, Ichiba M, Payton NM, Oishi H, Hara M. Simultaneous measurement of urinary total nicotine and cotinine as biomarkers of active and passive smoking among Japanese individuals. Environmental health and preventive medicine. 2013;18(3):244-50.

22. Aurrekoetxea JJ, Murcia M, Rebagliato M, Lopez MJ, Castilla AM, Santa-Marina L, et al. Determinants of self-reported smoking and misclassification during pregnancy, and analysis of optimal cut-off points for urinary cotinine: a crosssectional study. BMJ Open. 2013;3(1).

23. Jung S, Lee IS, Kim SB, Moon CS, Jung JY, Kang YA, et al. Urine Cotinine for Assessing Tobacco Smoke Exposure in Korean: Analysis of the Korea National Health and Nutrition Examination Survey (KNHANES). Tuberculosis and respiratory diseases. 2012;73(4):210-8.
24. Smoking and Tobacco Used [Internet]. National Center for Chronic Disease Prevention and Health Promotion,. 2016 [cited 31 July 2017].

25. Prevention CfDCa. Adult Tobacco Use Questions on the National Health Interview Survey 1997 -Forward. In: Prevention CfDCa, editor. Atlanta, USA: Centres for Disease Control and Prevention; 1997.

26. Kim S. Overview of Cotinine Cutoff Values for Smoking Status Classification. International journal of environmental research and public health. 2016;13(12).

27. Jamal R, Syed Zakaria SZ, Kamaruddin MA, Abd Jalal N, Ismail N, Mohd Kamil N, et al. Cohort Profile: The Malaysian Cohort (TMC) project: a prospective study of non-communicable diseases in a multi-ethnic population. Int $\mathrm{J}$ Epidemiol. 2015;44(2):423-31.

28. Cattaneoa R, Alegretti, A.P., Sagebin, F.R., Abreu, C.M.D., Petersen, G.O. \& Chatkin, J.M. Validation of a high-performance liquid chromatography method for the determination of cotinine in urine. Revista Brasileira de Toxicologia 2006;19(1):25-31.

29. Unal I. Defining an Optimal Cut-Point Value in ROC Analysis: An Alternative Approach. Computational and mathematical methods in medicine. 2017;2017:3762651.

30. Hong J.W NJH, Kim D. J.,. The prevalence of and factors associated with urinary cotinine-verified smoking in Korean adults: The 2008-2011 Korea National Health and Nutrition Examination Survey Jae Won Hong, Jung Hyun Noh, Dong-Jun Kim Plos One. 2018.

31. Hukkanen J, Jacob P, 3rd, Benowitz NL. Metabolism and disposition kinetics of nicotine. Pharmacol Rev. 2005;57(1):79-115.

32. Tricker AR. Nicotine metabolism, human drug metabolism polymorphisms, and smoking behaviour. Toxicology. 2003;183(1-3):151-73.

33. Avila-Tang E, Al-Delaimy WK, Ashley DL, Benowitz N, Bernert JT, Kim S, et al. Assessing secondhand smoke using biological markers. Tobacco control. 2013;22(3):164-71.

34. Signorello LB, Cai Q, Tarone RE, McLaughlin JK, Blot WJ. Racial differences in serum cotinine levels of smokers. Disease markers. 2009;27(5):187-92.

35. Gilligan C, Sanson-Fisher R, Eades S, Wenitong M, Panaretto K, D'Este C. Assessing the accuracy of selfreported smoking status and impact of passive smoke exposure among pregnant Aboriginal and Torres Strait Islander women using cotinine biochemical validation. Drug Alcohol Rev. 2010;29(1):35-40.

36. Pearce MS, Mann KD, Singh G, Davison B, Sayers SM. Prevalence and validity of self-reported smoking in Indigenous and non-Indigenous young adults in the Australian Northern Territory. BMC public health. 2014; 14:861.

37. Jeemon P, Agarwal S, Ramakrishnan L, Gupta R, Snehi U, Chaturvedi V, et al. Validation of selfreported smoking status by measuring serum cotinine levels: an Indian perspective. Natl Med J India. 2010;23(3):134-6. 
38. Wielkoszyński $\mathrm{T}$, et al. The enzyme-linked immunosorbent assay (ELISA) method for nicotine metabolites determination in biological fluids. J Pharm Biomed Anal. 2009;49(5):1256-60.

39. Massadeh AM GA, Omari KW. A single-step extraction method for the determination of nicotine and cotinine in Jordanian smokers' blood and urine samples by RP-HPLC and GC-MS. J Chromatogr Sci 2009;47(2):170-7.
40. Dunlop AJ, et al. Determination of cotinine by LCMS-MS with automated solid-phase extraction. . Journal of Chromatographic Science 2013;52(4):35156.

41. Seccareccia F, et al. . Serum cotinine as a marker of environmental tobacco smoke exposure in epidemiological studies: the experience of the MATISS project. Eur J Epidemiol. 2003;18(6):48792. 